\title{
Permeation of Tank C-103 Sludge Simulant by Organic Solvent
}

\author{
M. A. Gerber
}

March 1995

Prepared for the U.S. Department of Energy under Contract DE-AC06-76RLO 1830

Pacific Northwest Laboratory

Operated for the U.S. Department of Energy by Battelle Memorial Institute 


\title{
DISCLAIMER
}

This report was prepared as an account of work sponsored by an agency of the United States Government. Neither the United States Government nor any agency thereof, nor Battelle Memorial Institute, nor any of their employees, makes any warranty, expressed or implied, or assumes any legal liability or responsibility for the accuracy, completeness, or usefulness of any information, apparatus, product, or process disclosed, or represents that its use would not infringe privately owned rights. Reference herein to any specific commercial product, process, or service by trade name, trademark, manufacturer, or otherwise does not necessarily constitute or imply its endorsement, recommendation, or favoring by the United States Government or any agency thereof, or Battelle Memorial Institute. The views and opinions of authors expressed herein do not necessarily state or reflect those of the United States Government or any agency thereof.

\author{
PACIFIC NORTHWEST LABORATORY \\ operated by \\ BATTELLE MEMORIAL INSTITUTE \\ for the \\ UNITED STATES DEPARTMENT OF ENERGY \\ under Contract DE-AC06-76RLO 1830
}

Printed in the United States of America

Available to DOE and DOE contractors from the

Office of Scientific and Technical Information, P.O. Box 62, Oak Ridge, TN 37831;

prices available from (615) 576-8401. FTS 626-8401.

Available to the public from the National Technical Information Service, U.S. Department of Commerce, 5285 Port Royal Rd., Springfield, VA 22161. 
PNL-10412

UC-601

\section{Permeation of Tank C-103 Sludge Simulant by Organic Solvent}

M.A. Gerber

March 1995

Prepared for

the U.S. Department of Energy

under Contract DE-AC06-76RLO 1830

Pacific Northwest Laboratory

Richland, Washington 99352 

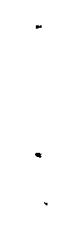


\section{Summary}

The plan for stabilizing underground storage tanks (USTs) calls for draining the supernate from the tanks; however, there is concern that draining the supernate from Tank C-103 will degrade safety in the tank. The sludge in Tank C-103 contains ranges in depth from 1 to $1.5 \mathrm{~m}$ and is covered by both an aqueous phase and a separate organic layer. The main concern is that draining the supernate will cause the solvent to permeate the sludge solids and provide a source of fuel for a fire on the surface of the drained sludge. The question of whether the solvent will permeate sludge that is 1 to $1.5 \mathrm{~m}$ deep after the tank is dewatered is the purpose of the tests conducted and described in this report.

Evaluation of the solvent permeation mechanism required the preparation of solvent, supernate, and sludge simulants based on the known chemistry of Tank C-103. Solvent and aqueous phase supernate simulants are based on the results of fiscal year 1994 sampling of the tank solvent and supernate. Sludge simulant is based on the chemical analyses of tank sludge samples retrieved in 1986.

Experiments were conducted with each simulant to evaluate solvent permeation under matric potentials ranging from $0.8 \mathrm{~m}$ to $1.8 \mathrm{~m}$ of supernate. These values were selected because the depth of sludge in Tank C-103 varies from 0.9 to $1.5 \mathrm{~m}$. The amount of solvent recovered for each experiment was recorded as well as the maximum amount of solvent that could be in the sludge based on solvent recovered from resuspended sludge and solvent not recovered. The wt \% of water remaining in the sludge was also recorded for each experiment, which was determined by measuring the weight of the sludge after drying it. The maximum solvent that could be in the sludge for tests $1 \mathrm{~A}, 2 \mathrm{~A}$, and $2 \mathrm{~B}$ was less than $1 \mathrm{~mL}$, which is considered to be within the accuracy expected for solvent loss under conditions of no permeation. Experiments $1 \mathrm{~B}$ and $2 \mathrm{C}$ showed indirect evidence of significant adsorption. Total of solvent not recovered was 1.08 and $1.47 \mathrm{~mL}$, respectively, which is significantly greater than that normally lost. Also, there is a trend of increasing solvent loss with increasing applied vacuum for both simulants. One difference that occurred in conducting experiments $1 \mathrm{~B}$ and $2 \mathrm{C}$ was that some solvent passed through the filter membrane and it is possible that at least a portion of the solvent was not recovered from the glass frit supporting the filter membrane, although about $0.1 \mathrm{~mL}$ of solvent was recovered by washing the frit with supernate with the system under vacuum.

There were two other sources of loss of solvent during recovery: 1) Organic films left behind on the filter reservoir, beakers, and separatory funnels. Using the solvent recovery value for experiment $2 \mathrm{~A}$, this source would account for about $0.15 \mathrm{~mL}$ of solvent. 2) A source that was not anticipated while conducting experiments $1 \mathrm{~A}, 2 \mathrm{~A}$ and $2 \mathrm{~B}$ was dissolution of the TBP present in the solvent into the water (about $200 \mathrm{~mL}$ ) used to resuspend the sludge to separate solvent. Experiments $1 \mathrm{~B}$ and $2 \mathrm{C}$ were modified to rinse the sludge and resuspend it using solvent equilibrated supernate. The fact that no solvent was recovered from the sludge in these experiments suggest that the solvent may be remaining, attached to the sludge particles even after resuspension.

One observation noted from the test results is that the finer sludge material tended to have a greater amount of solvent loss compared to the coarser sludge material at comparable levels of vacuum. At this time, there is no explanation. 
Based on the experimental results, there appears to be some solvent permeation into sludge simulants under conditions representative of sludge 1 to $1.5 \mathrm{~m}$ deep. However, the amount of solvent that permeated the simulants tested was still relatively modest (1.5 wt \% to $3.4 \mathrm{wt} \%)$. These quantities are less than $10 \%$ of the total liquid entrained in the sludge at the conclusion of each experiment and may not cause a degradation of safety, although that remains to be determined.

There are two important points that need to be considered in evaluating these results. First, one of the samples of sludge taken from Tank C-103 in 1986 had a reported 50\% volume particle diameter of $49.5 \mu \mathrm{m}$, which is 3 times greater than the $50 \%$ volume particle diameter in the coarser sludge simulant tested. Second, the interfacial tension between the solvent and aqueous phase simulants was 2 to 4 times greater than that reported for solvent and aqueous phases taken from Tank C-103 in 1993. Both of these points suggest that solvent permeation could occur to a greater degree in the actual tank.

It is recommended that an even coarser sludge simulant be tested to better bound the coarser $50 \%$ volume particle diameter measurement for sludge samples recovered from the tank. Similarly, tests with a solvent supernate system having a lower interfacial tension needs to be tested. Further effort is also needed to determine whether the unrecovered solvent was in the sludge, and whether solvent permeating the glass frit is a significant source of solvent loss. 


\section{Contents}

Summary $\quad \ldots \ldots \ldots \ldots \ldots \ldots \ldots \ldots \ldots \ldots \ldots \ldots \ldots \ldots$ ii

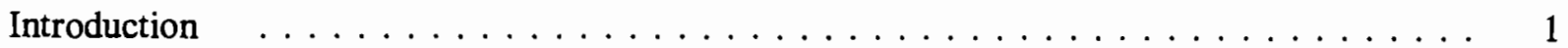

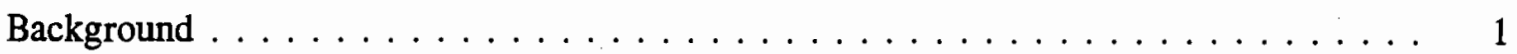

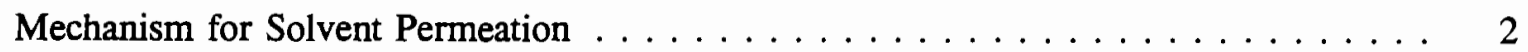

Preparation of Simulant Materials $\ldots \ldots \ldots \ldots \ldots \ldots \ldots$

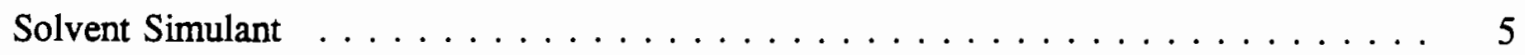

Aqueous Phase Simulant $\ldots \ldots \ldots \ldots \ldots \ldots \ldots$

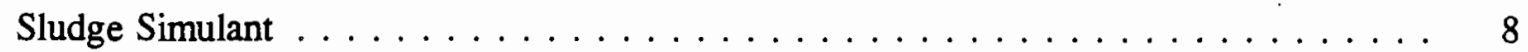

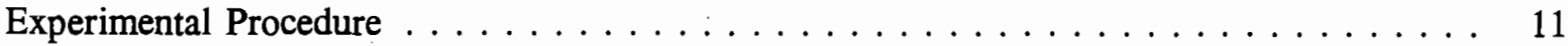

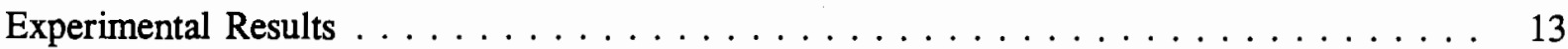

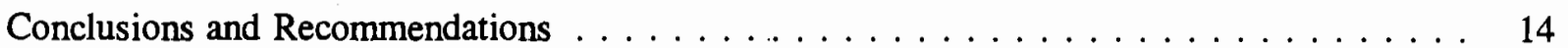

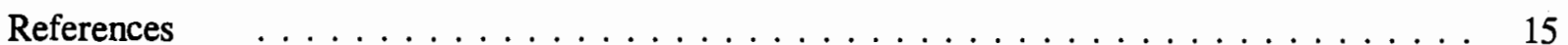




\section{Figures}

1. (a) Ideal Profile of Sludge and Liquids in Tank (b) Profile of Drained Tank $\ldots \ldots$. . . 1

2. Moisture Profile of a Porous Solid in a Pool of Water $\ldots \ldots \ldots \ldots$

3. Capillary Rise for Various Soils $\ldots \ldots \ldots \ldots \ldots \ldots \ldots$

4. Particle Size Distribution for Simulant $1 \ldots \ldots \ldots \ldots \ldots \ldots$

5. Particle Size Distribution for Simulant $2 \ldots \ldots \ldots \ldots \ldots \ldots \ldots$

6. Diagram of Experimental Apparatus for Solvent Permeation Experiments $\ldots \ldots \ldots 12$

\section{Tables}

1. Surface Tension of Various Fluid Pairs $\ldots \ldots \ldots \ldots$

2. Components Determined by GC/MS Analysis of the Organic Layer . . . . . . . . 5

3. Inorganic Analytes Found in Tank C-103 Aqueous Phase $\ldots \ldots \ldots \ldots$

4. Compositions of Aqueous Phase Simulant $\ldots \ldots \ldots \ldots \ldots$

5. Composition of 1986 Tank C-103 Sludge Samples $\ldots \ldots \ldots \ldots \ldots$

6. Solids Used in Preparing Simulant $1 \ldots \ldots \ldots \ldots \ldots$

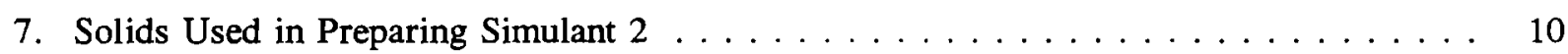

8. Experiment Results of Permeation Evaluation of Sludge Simulants $\ldots \ldots \ldots$ 


\section{Introduction}

The sludge in Tank C-103 contains ranges in depth from 1 to $1.5 \mathrm{~m}$ and is covered by both an aqueous phase and a separate organic layer. The organic layer is primarily composed of tributyl phosphate (TBP) and normal paraffinic hydrocarbons (NPH) $\left(\mathrm{C}_{10}\right.$ to $\left.\mathrm{C}_{14}\right)$ floating on the surface of the aqueous supernate (free liquids) in the tanks. The plan for stabilizing underground storage tanks (USTs) calls for draining the supernate from the tanks; however, there is concern that draining the supernate from Tank C-103 will degrade safety in the tank. The main concern is that the solvent will permeate the sludge solids and provide a source of fuel for a fire on the surface of the drained sludge. Two questions need to be answered to address this concern: 1) Will the solvent permeate sludge that is 1 to $1.5 \mathrm{~m}$ deep if the tank is dewatered, and 2) will the entrained solvent burn on the surface if an ignition source is provided? This appendix describes only the tests conducted to determine whether the solvent will permeate the surface.

\section{Background}

Ideally, the sludge layer in a tank maintains its shape (Figure 1[a]) while the supernate is drained from the bottom of the tank, maintaining a flat, horizontal surface for the organic phase to contact. But in fact, some solids nearest the pump are removed along with the liquid during draining, creating a depression on the sludge surface around the pump (Figure 1[b]) that provides a direct path for free supernate and solvent to drain from the sludge surface to the pump. In addition, the surface of the sludge fractures immediately after the free supernate is removed because the sludge begins to consolidate. These cracks trap the solvent in isolated pockets at or near the surface during draining.
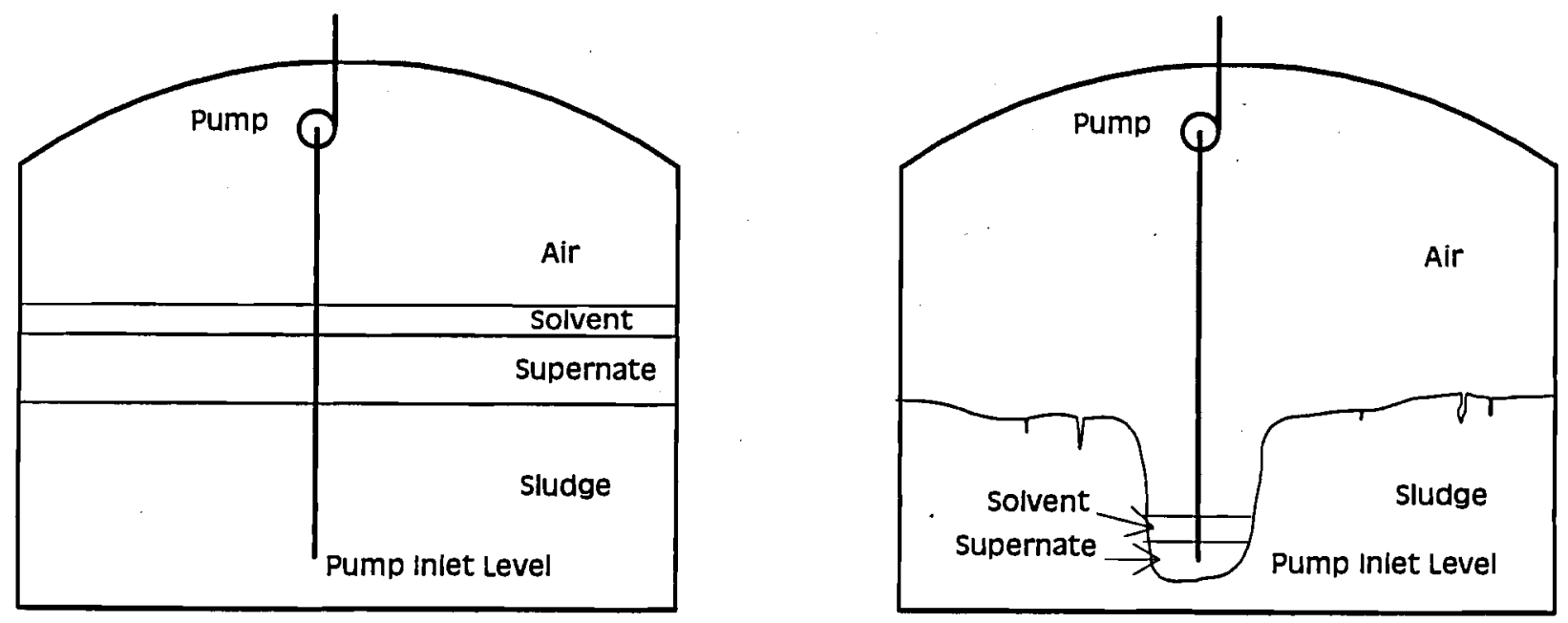

Figure 1. (a) Ideal Profile of Sludge and Liquids in Tank (b) Profile of Drained Tank 


\section{Mechanism for Solvent Permeation}

The permeation behavior of a solvent into a porous material saturated with supernate is very similar to that between air and supernate. The principle differences are those inherent in the properties of the air and solvent and the added pressure applied against the water in the porous material due to the height of the solvent above the supernate phase in the solid. This concept will be explained in this section.

Figure 2 shows a typical moisture profile for water in a porous solid resting in a pool of water. The total specific energy potential (energy available to do work per unit mass) at any point in the solid above the water level in the pool is defined by Freeze and Cherry (1979) as

$$
\Phi=\mathrm{gz} / \mathrm{g}_{\mathrm{c}}+\left(\mathrm{P}_{\mathrm{r}}-\mathrm{P}_{\mathrm{a}}\right) /(\rho)
$$

where $\Phi=$ total potential ( $\mathrm{ft}-\mathrm{lb}_{\text {force }} / \mathrm{lb}_{\text {mass }}$ ), (or just $\mathrm{ft}$ by equating unit weight and mass).

$\mathrm{g}=$ gravity $\left(32.17 \mathrm{ft} / \mathrm{sec}^{2}\right)$

$\mathrm{z}=$ height above a reference point of zero matric potential

$\mathrm{g}_{\mathrm{c}}=$ gravitational constant $\left(32.7 \mathrm{ft}-1 \mathrm{~b}_{\text {mass }} / 1 \mathrm{~b}_{\text {force }}-\mathrm{sec}^{2}\right)$

$\mathbf{P}=$ pressure measured at a point in the solid (either hydraulic or tension pressure)

$\mathrm{P}_{\mathrm{o}}=$ reference pressure at height $\mathrm{z}=0$

$\rho=$ density of the fluid.

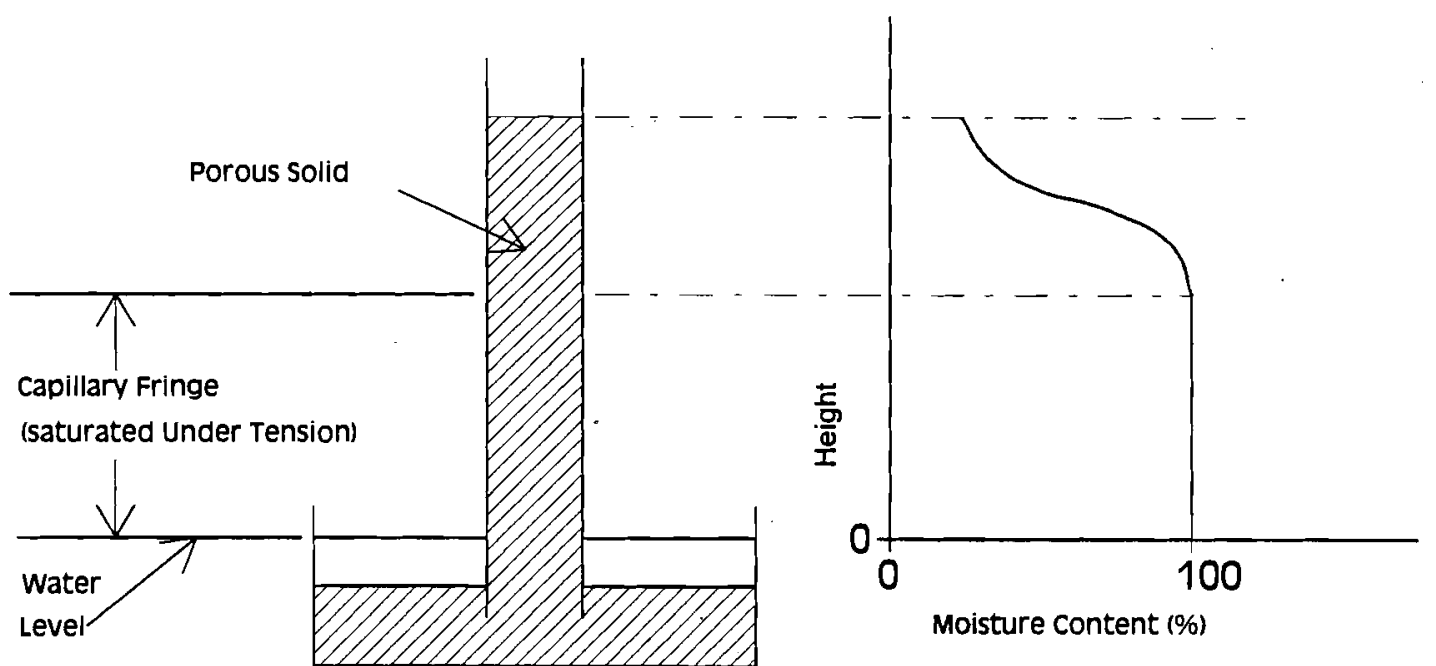

Figure 2. Moisture Profile of a Porous Solid in a Pool of Water 
The first term on the right of Equation (1) is the gravitational potential due to the elevation of the point of interest above a reference point, such as the pump inlet in a UST. The second term, the matric potential due to the tension exerted on the liquid in the pores due to its surface tension, has a negative value (i.e., a measure of the pull of the surface tension against gravity as water undergoes a capillary rise). Other terms associated with energy potential, such as chemical energy, are not considered.

The absolute value of the term $\left(\mathrm{P}_{1}-\mathrm{P}_{2}\right)$ represents the capillary pressure of the supernate at the air/supernate interface. The value of the capillary pressure above which air can enter the pores of the solid is called the air entry pressure (bubbling pressure) of the supernate for that particular material. The capillary pressure is also the pressure that would be measured by a manometer if the reference pressure for the manometer is same as the air pressure.

The height of the capillary rise (in which all pores remain saturated under tension) can be related to matric potential at equilibrium using equation (1) and by setting the total energy potential to zero. As the capillary pressure increases (the matric potential becomes more negative) at points above the capillary fringe, air enters the pores and displaces a portion of the capillary water and the porous material becomes progressively less saturated at equilibrium as shown in Figure 2. Eventually, at very high capillary pressure, it reaches a residual saturation level where the remaining water is immobilized along the solid surfaces.

As previously discussed, the behavior of an air/supernate system and a solvent/supernate system are essentially the same if the depth of the solvent is negligible. For a solvent/supernate system, the solvent entry pressure can be equated to the air entry pressure (i.e., that capillary pressure above which the solvent would enter the pores of the solid). The difference between the values of the solvent entry pressure and the air entry pressure is largely due to differences in values of the interfacial tension for solvent/supernate system and surface tension for the air/supernate system. The capillary rise for an oil/supernate system is less for air because the surface tension of the solvent is much closer to that of water than is air. Values for surface tension of selected liquids are listed in Table 1.

Table 1. Surface Tension of Various Fluid Pairs

\begin{tabular}{l}
\multicolumn{1}{c}{ Fluid Pair } \\
Air/water \\
Air/dodecane \\
Air/Soltrol \\
Soltrol/water \\
Air/TBP \\
Air/water-saturated TBP \\
Air/TBP saturated water \\
TBP/water \\
TBP/5M HNO $\mathrm{HA}_{3}(\mathrm{Aq})$ \\
Air/8.9M $\mathrm{HNO}_{3}(\mathrm{Aq})$ \\
Air/2.8M $\mathrm{HNO}_{3}(\mathrm{Aq})$ \\
Air/7.0M $\mathrm{NaNO}_{3}(\mathrm{Aq})$ \\
Air/5.0M $\mathrm{NaOH}_{\text {(Aq) }}$
\end{tabular}

Surface Tension (mN/m)

70.79

24.9

24.23

44.21

27.59

42.1

35.6 .

$7.4-8.0$

8.7

68.3

70.9

80.3

83.1
Reference

Lenhard and Parker (1988)

Riddick and Bunger (1970)

Lenhard and Parker (1988)

Lenhard and Parker (1988)

Burger (1984)

Burger (1984)

Burger (1984)

Burger (1984)

Burger (1984)

Dean (1973)

Dean (1973)

Dean (1973)

Dean (1973) 
Several things can be inferred from the surface tensions of various pairs. First, it is generally assumed that the surface tension of a pair of immiscible liquids (water/dodecane) is approximately the difference of the air/liquid surface tensions of the two liquids). However, it can be seen that an organic such as TBP, which is sparingly soluble in water $(0.39 \mathrm{~g} / \mathrm{L})$ and nitric acid $(0.82 \mathrm{~g} / \mathrm{L}$ in $5.2 \mathrm{M}$ $\mathrm{HNO}_{3}$ ), produces a significantly reduced surface tension of the liquid pair compared to the air/liquid values. However, the solubility of TBP in salt solutions is decreased due to salting out, which may make the behavior of the TBP/aqueous solution pair more like a truly immiscible pair. The presence of other polar solvents in the TBP could offset this, however, because most polar solvents in water reduce the air/liquid surface tension (Dean 1973). The presence of salts also appears to increase the surface tension of the aqueous solution/air pair. It may be inferred from these values that it is possible that the oil will displace the water in the solids relatively easily but that air may not be able to displace the oil in the solids.

The physical properties of the sludge solids are also important because they also affect the magnitude of the capillary rise for any fluid pair. The magnitude of the capillary rise in tank sludge is important because it determines whether the sludge height above the inlet pump is greater than the capillary rise leading to conditions of desaturation in respect to air or solvent.

Figure 3 shows that the capillary rise can range from a few centimeters for relatively coarse material to as much as $5 \mathrm{~m}$ for very fine material (clay particle diameters range from 1 to $20 \mu \mathrm{m}$ ). The type of solid is also important if the supernate contains organic constituents that can adsorb on the particle surfaces and reduce their hydrophilic character.

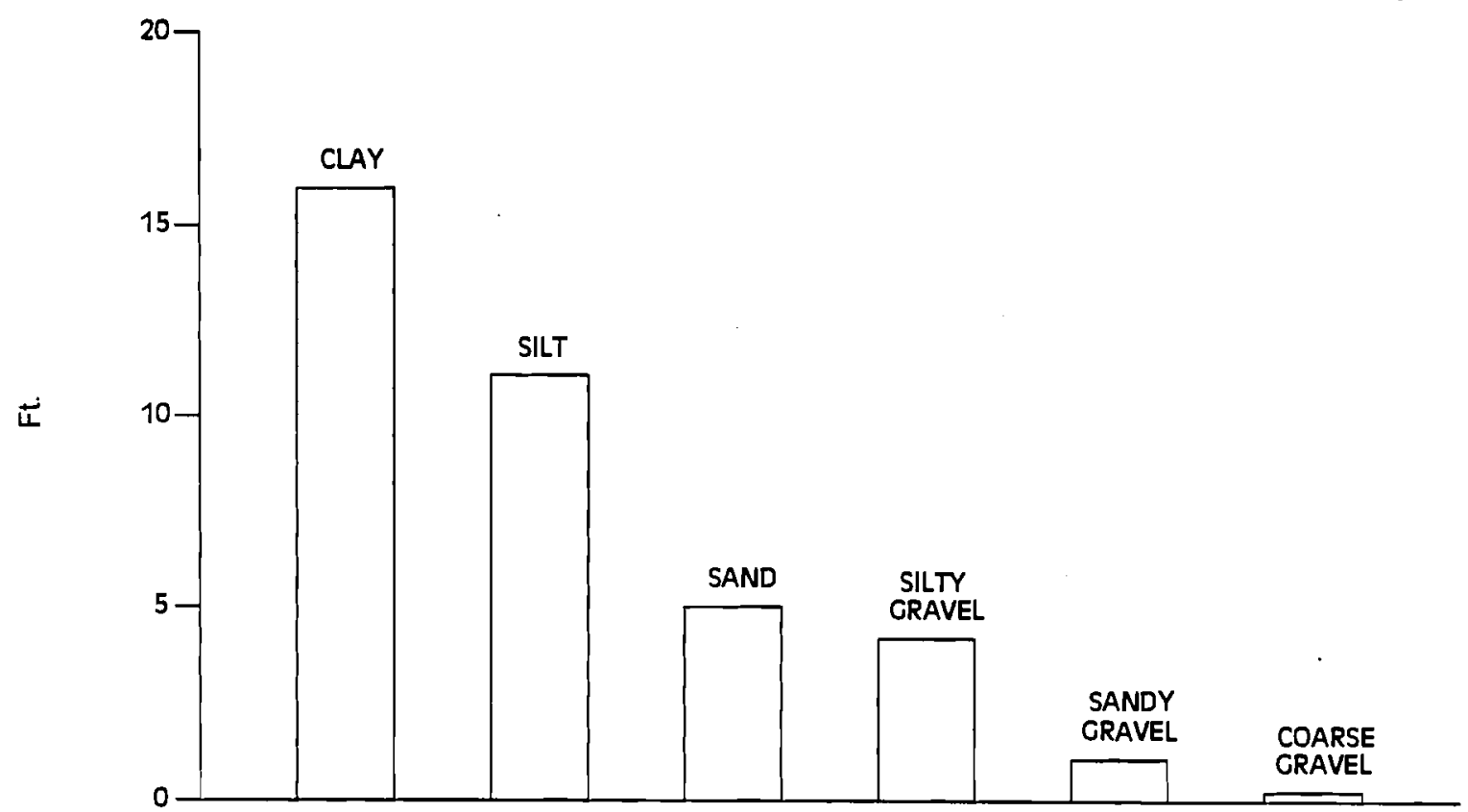

Figure 3. Capillary Rise for Various Soils 
Another property of the sludge in the USTs is that it is not fully consolidated due to the colloidal behavior of the sludge particles and will shrink as it is drained, maintaining saturation as supernate is drained until enough contact between adjacent particles occur to form a rigid, porous matrix.

\section{Preparation of Simulant Materials}

Evaluation of the solvent permeation mechanism required the preparation of solvent, supernate, and sludge simulants based on the known chemistry of Tank C-103. Solvent and aqueous phase supernate simulants are based on the results of fiscal year 1994 sampling of the tank solvent and supernate (Pool and Bean 1994). Sludge simulant is based on the chemical analyses of tank sludge samples retrieved in 1986 (Weiss and Schull).

\section{Solvent Simulant}

Solvent samples retrieved from Tank C-103 were analyzed by Pacific Northwest Laboratory (PNL) in December 1993, using gas chromatography/mass spectrometry (GC/MS) (Pool and Bean 1994). According to these results, the TBP, dibutylbutyl-phosphate (DBBP), and NPH account for $64 \%, 2.6 \%$, and $33.4 \%$ by weight, respectively, of the identified constituents in the organic phase. However, collectively these account for only $73.7 \mathrm{wt} \%$ of the organic phase. The remaining $26.3 \mathrm{wt} \%$ of the constituency is unknown. The known composition of the organic phase is shown in Table 2.

Table 2. Components Determined by GC/MS Analysis of the Organic Layer

\begin{tabular}{|c|c|c|c|}
\hline Component & Retention Time, min. & Wt\% & Relative W \\
\hline Dodecane & 10.51 & 2.0 & 3.8 \\
\hline Alkane & 10.74 & 0.2 & 0.3 \\
\hline Alkane & 11.85 & 1.1 & 1.5 \\
\hline Tridecane & 12.38 & 11.4 & 15.5 \\
\hline Alkane & 13.23 & 0.5 & 0.6 \\
\hline Alkane & 13.72 & 1.0 & 1.3 \\
\hline Tetradecane & 14.17 & 6.0 & 8.1 \\
\hline Alkane & 15.17 & 0.7 & 1.0 \\
\hline Pentadecane & 15.84 & 0.9 & 1.2 \\
\hline DBBP & 17.6 & 1.9 & 2.6 \\
\hline TBP & 18.09 & 47.2 & 64.0 \\
\hline Total & & 73.7 & 100.0 \\
\hline
\end{tabular}

The relative quantities of dodecane, tridecane, tetradecane and pentadecane are consistent with commercially available normal paraffin hydrocarbon reported by Wilbourn (1977). The solvent simulant was prepared based on the relative volume proportions NPH, TBP and dibutyl phosphate (DBP). 


\section{Aqueous Phase Simulant}

Aqueous phase samples were also retrieved from Tank C-103 and analyzed by PNL in December 1993 (Bean and Poole 1994). Inorganic analysis included ion chromatography (IC) for anions, and inductively coupled plasma/atomic emission spectrometry (ICP/AES) for cations. Ammonia was analyzed using well-established ion selective electrode methodology according to procedure PNL-ALO-226 "Ammonia (N) in Aqueous Samples." Total organic carbon (TOC) and total inorganic carbon (TIC) were analyzed using the hot persulfate oxidation/coulometry detector method PNL-AALO-381 REV. 0 "Determination of TC, TOC, and TIC in Radioactive Liquids, Soils, and Sludges by Hot Persulfate Method." Table 3 shows the analysis of the aqueous phase from Tank C-103 for various analytes.

Table 3. Inorganic Analytes Found in Tank C-103 Aqueous Phase

$\begin{array}{llll}\text { ICP Elements } & \underline{\mu \mathrm{g} / \mathrm{g}} & \underline{\mathrm{IC} \text {-Anions }} & \underline{\mu \mathrm{g} / \mathbf{g}} \\ \mathrm{P} & 2,350 & \mathrm{~F}^{-} & 1,100 \\ \mathrm{Na} & 30,400 & \mathrm{Cl}^{-} & 400 \\ \mathrm{Ni} & 67 & \mathrm{NO}_{2-} & 23,000 \\ \mathrm{Cd} & 0.8 & \mathrm{NO}_{3}^{-} & 2,450 \\ \mathrm{Ca} & 10 & \mathrm{PO}_{4}{ }^{3-} & 2,000 \\ \mathrm{Ag} & 11 & \mathrm{SO}_{4}{ }^{2-} & 3,000 \\ \mathrm{Cr} & 53 & & \\ \mathrm{Fe} & 3 & \text { Ammonia } & 215 \\ \mathrm{~K} & 300 & & \\ \mathrm{Mo} & 10 & \text { TOC } & 6700 \\ \mathrm{U} & 1950 & & \\ \mathrm{Zr} & 280 & \text { TIC } & 4800\end{array}$

Table 4 shows the composition of the aqueous phase simulant that was used in the experiments. This table also shows for comparison the key analytes found in actual tank aqueous samples on a molar basis.

The total sodium in the simulant is less than that in the actual waste supernate. Based on the TIC measured in the actual waste (Table 3 ) it is likely that the balance of sodium is a counterion to carbonate anions in the waste which would account for the TIC. However, there is no analysis for carbonate to confirmation this hypothesis. A second simulant is being prepared to include sodium carbonate for future limited tests.

One difficulty in preparing the simulant has been the selection of organic species to account for the total organic carbon in the Tank C-103 supernate. The TOC in the tank waste is significant in that some organics believed to be in the tank may interact with the solid phase particle surfaces, thereby altering their wettability by solvent. Also, the presence of small quantities of certain organics can significantly reduce the interfacial tension between the supernate and organic liquid phases. Both of these effects could promote permeation of the sludge by organics. 
Table 4. Composition of Aqueous Phase Simulant

\begin{tabular}{l} 
Simulant \\
Concentration \\
Component \\
\hline
\end{tabular}

$\mathrm{NaNO}_{2}$

$\mathrm{Na}_{2} \mathrm{SO}_{4}$

$\mathrm{NaNO}_{3}$

$\mathrm{Na}_{2} \mathrm{HPO}_{4}$

$\mathrm{NaF}$

$\mathrm{NaCl}$

$\mathrm{NaOH}$

Total Na

TOC

Simulant
Concentration
(mol/L)

0.50

0.031

0.039

0.023

0.053

0.011

(pH 9.8)

.711

0.55 wt \%
Tank C-103

Concentration

Constituent

$\mathrm{NO}_{3}^{-}$

$\mathrm{SO}_{4}^{-2}$

$\mathrm{NO}_{3}^{-}$

$\mathrm{HPO}_{4}^{-2}$

$\mathrm{F}^{-}$

$\mathrm{Cl}^{-}$

$\mathrm{OH}^{-}$

Total $\mathrm{Na}$

TOC
Tank C-103

Concentration

(mol/L)

0.53

0.033

0.042

0.023

0.062

0.012

(pH 9.8)

1.23

$0.67 \mathrm{wt} \%$

The aqueous phase in Tank C-103 has not been analyzed for organic species. Consequently, the organic species present can only be speculated. Possible sources for TOC in the aqueous phase are TBP, and its degradation product DBP; organic acid salts resulting from degradation of NPH products; and complexants added to the tank along with their degradation products. Other expected solvent degradation products including alcohols, ketones, and aldehydes are relatively volatile and were not identified in the solvent recovered from Tank C-103.

Interfacial tension measurements were made for two samples containing solvent and supernate phases retrieved from Tank $\mathrm{C}-103$. Interfacial tension values ranged from $<1$ to 2 dyne $/ \mathrm{cm}$. However, the method used was not a standard method. In the standard method, a clean du Noüy ring (or platinum coupon) is immersed in the aqueous phase prior to adding the solvent phase. The platform containing the sample is slowly lowered until the ring encounters the interface level (from below it) and a measurement of the force applied on the ring due to interfacial tension is recorded. This method requires using separated phases for each measurement and would have required a separation step between measurements because of the small quantities of tank solvent and supernate samples available. The method used involved placing the ring (coupon) in the solvent after it had been layered on top of the supernate and then raising the platform until the ring encountered the interface (from above it) and taking a measurement at the interface level. The latter method can give an incorrect value because the solvent precoats the ring changing its wetting properties.

The TOC of the supernate simulant was obtained by adding a quantity sodium citrate, sodium EDTA (ethylenediaminetetraacetic acid), sodium octanoate, and sodium oxalate to produce a concentration of $0.1 \mathrm{wt} \%$ TOC of each; and sufficient DBP to produce a concentration of $0.15 \mathrm{wt} \%$ TOC. The TBP in the solvent was also expected to contribute to the TOC in the supernate.

The nonstandard method was used to compare the interfacial tension of the aqueous and organic phase simulants, but using a platinum coupon. The coupon was used because it does not require corrections to the measured force as does the de Noüy Ring. The interfacial tension of the supernate containing the organics was 4.6 dyne $/ \mathrm{cm}$. This value also compares to a value of 7.4 dyne $/ \mathrm{cm}$ obtained for the solvent and supernate that did not contain the organic salts. 


\section{Sludge Simulant}

Two sludge simulants were prepared based on chemical composition data (Table 5) for sludge samples retrieved from Tank C-103 in 1986 (Weiss and Schull). The two simulants differed in their particle size distributions to bound the expected range of particle size distributions for tank C-103. The particle diameter, in which $50 \%$ of the particles in the sample have smaller diameters, were reported for the tank sludge samples obtained in 1986 from two different locations within the tank. These values were $11.5 \mu \mathrm{m}$ and $49.5 \mu \mathrm{m}$, even though their elemental compositions were very similar.

Table 5. Composition of 1986 Tank C-103 Sludge Samples

\begin{tabular}{cc} 
Constituent & $\begin{array}{c}\text { Average Concentration } \\
(\mu \mathbf{m o l} / \mathbf{g})\end{array}$ \\
\cline { 3 - 3 } Silicon & 2513 \\
Sodium & 2196 \\
Iron & 1554 \\
Aluminum & 537 \\
Calcium & 277 \\
Magnesium & 255 \\
Zirconium & 135 \\
Phosphorus & 134 \\
Nickel & 49 \\
Nitric Acid & 45 \\
Manganese & 45 \\
Potassium & 36 \\
Other & 92
\end{tabular}

Simulant 1 was prepared by combining a mixture of $25.8 \%$ solids in the proportions listed in Table 6 and $74.5 \%$ supernate simulant. After mixing the solid components with the aqueous phase solution, $1 \mathrm{M} \mathrm{NaOH}$ solution was added until $\mathrm{pH}$ reached 12 . The sludge was then stirred for 3 hours and final $\mathrm{pH}$ was adjusted to 9.8 by addition of $1 \mathrm{M} \mathrm{HNO}_{3}$. Because a significant amount of $\mathrm{NaNO}_{3}$ was generated during the $\mathrm{pH}$ adjustment process, the supernate now contained more $\mathrm{NaNO}_{3}$ than desired. Therefore, drainable supernate was removed by centrifuge and replaced with equal amounts of new aqueous phase solution. The viscous mixture was then stirred overnight. The resulting sludge was reddish brown in color and had a consistency similar to wet clay. The particle size distribution was determined using a Microtrac Full-Range Particle Analyzer and using a solids loading index of about 0.75 . The particle size distribution is shown in Figure 4 . The $50 \%$ volume particle diameter was $4.55 \mu \mathrm{m}$. 
Table 6. Solids Used in Preparing Simulant 1

\begin{tabular}{|c|c|c|}
\hline Component & $\mathrm{Wt} \%$ & $\begin{array}{l}\text { Primary Particle } \\
\text { Size, } \mu \mathrm{m} \\
\end{array}$ \\
\hline $\mathrm{Fe}(\mathrm{OH})_{3}$ & $11.1 \%$ & 0.01 \\
\hline $\mathrm{SiO}_{2}$ & $10.1 \%$ & 0.06 \\
\hline $\mathrm{Al}(\mathrm{OH})_{3}$ & $2.0 \%$ & 0.250 \\
\hline $\mathrm{AlOOH}$ & $0.7 \%$ & 0.005 \\
\hline $\mathrm{Ca}_{10}(\mathrm{OH})_{2}\left(\mathrm{PO}_{4}\right)_{6}$ & $1.9 \%$ & 4.0 \\
\hline
\end{tabular}

Aqueous phase total $=74.2 \mathrm{wt} \%$ of sludge

\begin{tabular}{lcl} 
Component & $\begin{array}{l}\text { Simulant } \\
(\mathrm{mol} / \mathrm{L})\end{array}$ & $\begin{array}{l}\text { Tank } \\
(\mathrm{mol} / \mathrm{L})\end{array}$ \\
\hline $\mathrm{NaNO}_{2}$ & 0.50 & 0.50 \\
$\mathrm{NaSO}_{4}$ & 0.031 & 0.031 \\
$\mathrm{NaNO}_{3}$ & 0.039 & 0.039 \\
$\mathrm{Na}_{2} \mathrm{HPO}_{4}$ & 0.023 & 0.023 \\
$\mathrm{NaF}$ & 0.053 & 0.053 \\
$\mathrm{NaCl}$ & 0.011 & 0.011 \\
$\mathrm{NaOH}$ & $(\mathrm{pH} \mathrm{9.8)}$ & $(\mathrm{pH} \mathrm{9.8)}$
\end{tabular}

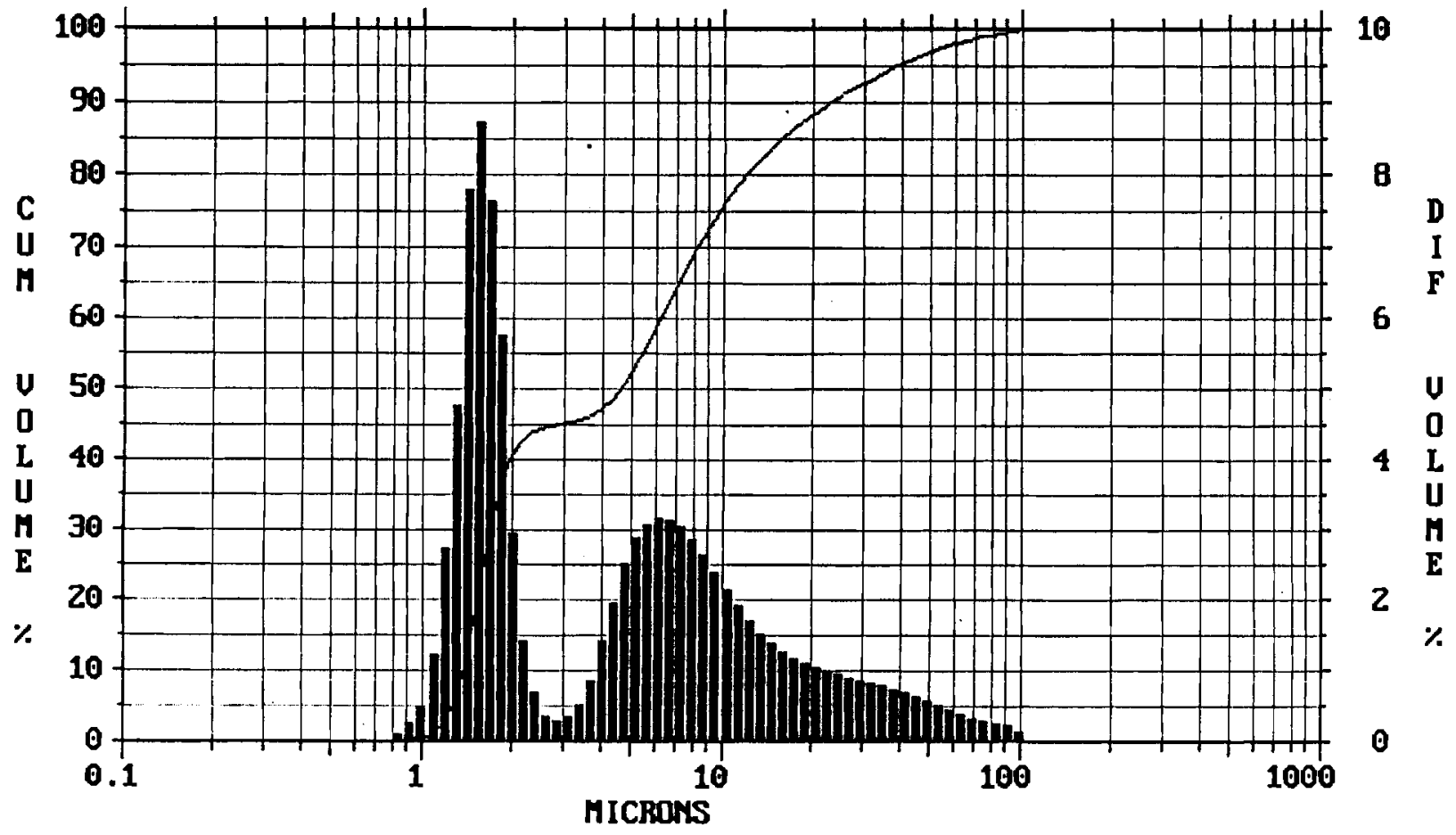

Figure 4. Particle Size Distribution for Simulant 1 
The solids in simulant 2 had the approximately the same composition as shown in Table 7 , but the primary particles were much larger to promote a coarser grained sludge. Preparation was similar to that for simulant 1 except that the aqueous phase initially mixed with the solids did not contain the sodium nitrate and was a neutral solution. This was done to minimize the excess nitrate present during synthesis. The $\mathrm{pH} 12$ solution was also stirred for 16 hours prior to neutralization. The resulting sludge had a purplish hue and a coarse appearance with a consistency more like silt. Small discrete particle grains could be observed in the simulant. The particle size distribution for this simulant, obtained using a loading index of 0.87 , is shown in Figure 5. The mean particle diameter (volume basis) was 15.78 .

Table 7. Solids Used in Preparing Simulant 2

Solid phase total $=25.9 \mathrm{wt} \%$ of sludge

\begin{tabular}{|c|c|c|}
\hline Component & Wt \% & $\begin{array}{l}\text { Primary Particle } \\
\text { Size, } \mu \mathrm{m}\end{array}$ \\
\hline $\mathrm{FeOOH}$ & $10.5 \%$ & $75-125$ \\
\hline $\mathrm{SiO}_{2}$ & $11.3 \%$ & 0.02 \\
\hline $\mathrm{Al}(\mathrm{OH})_{3}$ & $0.5 \%$ & 7.5 \\
\hline $\mathrm{AlOOH}$ & $1.5 \%$ & 0.005 \\
\hline $\mathrm{Ca}_{10}(\mathrm{OH})_{2}\left(\mathrm{PO}_{4}\right)_{6}$ & $2.1 \%$ & 0.004 \\
\hline
\end{tabular}

Aqueous phase total $=\mathbf{7 4 . 1} \mathrm{wt} \%$ of sludge

\begin{tabular}{|c|c|c|}
\hline Component & $\begin{array}{l}\text { Simulant } \\
(\mathrm{mol} / \mathrm{L})\end{array}$ & $\begin{array}{l}\text { Tank } \\
(\mathrm{mol} / \mathrm{L})\end{array}$ \\
\hline $\mathrm{NaNO}_{2}$ & 0.49 & 0.50 \\
\hline $\mathrm{NaSO}_{4}$ & 0.032 & 0.031 \\
\hline $\mathrm{NaNO}_{3}$ & 0.039 & 0.039 \\
\hline $\mathrm{Na}_{2} \mathrm{HPO}_{4}$ & 0.023 & 0.023 \\
\hline $\mathrm{NaF}$ & 0.053 & 0.053 \\
\hline $\mathrm{NaCl}$ & 0.011 & 0.011 \\
\hline $\mathrm{NaOH}$ & (pH 9.8) & (pH 9.8) \\
\hline
\end{tabular}




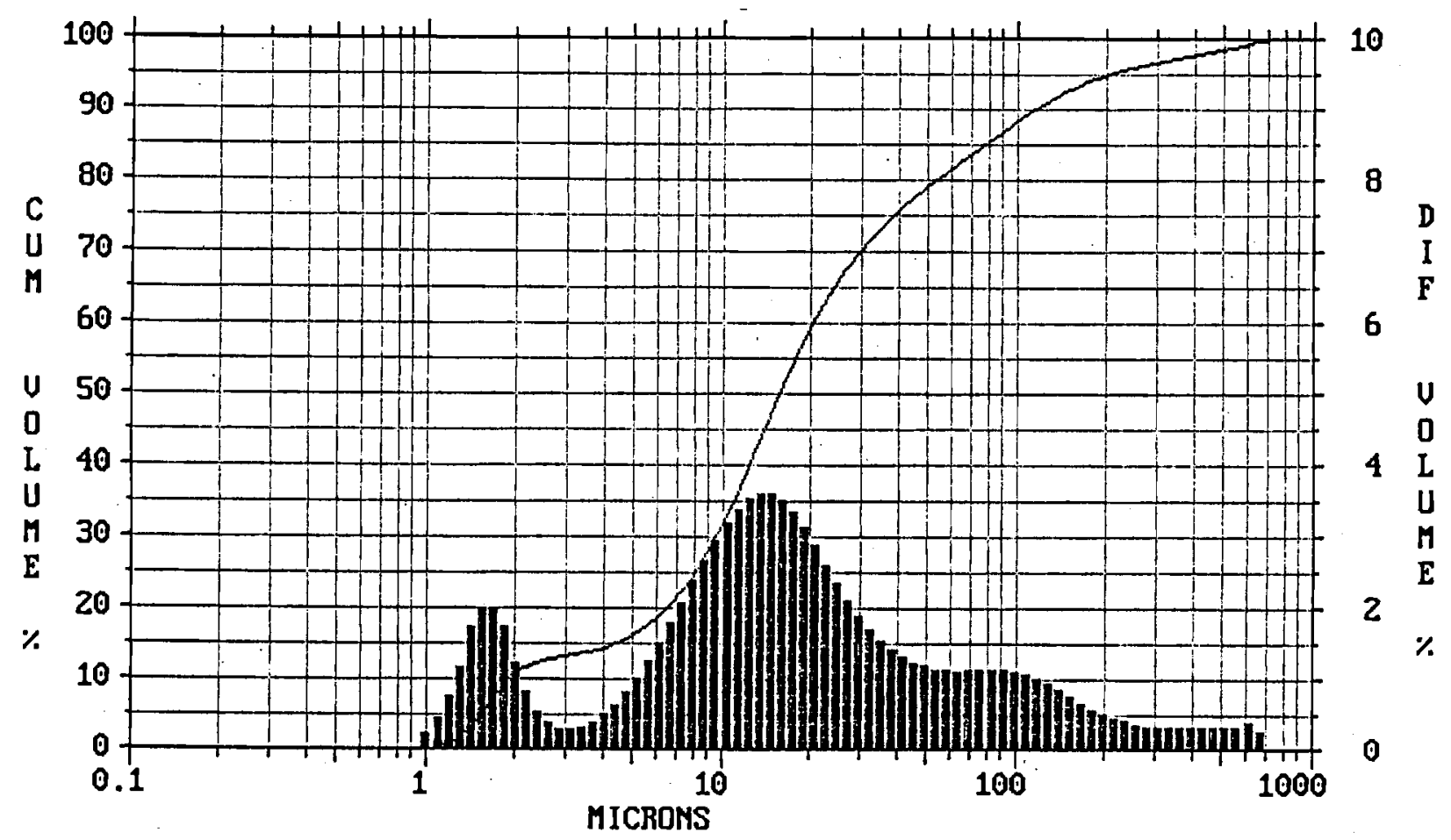

Figure 5. Particle Size Distribution for Simulant 2

\section{Experimental Procedure}

The experimental apparatus used to conduct the solvent permeation experiments is shown in Figure 6. The apparatus is based on the tension table design used to measure water retention in soils (Carter 1993). This apparatus is also referred to as a hanging water column. The filter consisted of a standard two-piece 47-mm microfilter and a supported plain $0.1-\mu \mathrm{m}$ nylon filter membrane to retain the sludge simulant and solvent. The graduated scale on the outside of the filter was used to measure sludge volume at the beginning of the experiment.

The matric potential at the filter is established by applying a vacuum to the bottom of the filter. The vacuum can be correlated to an equivalent height of supernate above the pump inlet in the sludge. Water displacement is measured in the buret, with a correction applied to account for differences in the height of the supernate in the buret and the average height of the sample.

Before conducting an experiment, $25 \mathrm{~mL}$ of the solvent and $250 \mathrm{~mL}$ of the supernate simulants were combined in a capped jar and agitated on a shaker table at $240 \mathrm{rpm}$ for at least 4 hours and then separated. Approximately 40 to $70 \mathrm{~mL}$ of sludge simulant was added to $200 \mathrm{~mL}$ of equilibrated supernate, stirred for about 24 hours, and then separated using a centrifuge. This step was done to pre-wet the solids with the organics in the supernate simulant. Approximately $50 \mathrm{~mL}$ of the supernate from the centrifuge was used to backfill the apparatus from the buret to the bottom of the filter. The sludge was added to the filter reservoir and about $20 \mathrm{~mL}$ of supernate added on top of it. After the sludge had settled enough to create clear liquid on top, $20 \mathrm{~mL}$ of equilibrated solvent was layered 


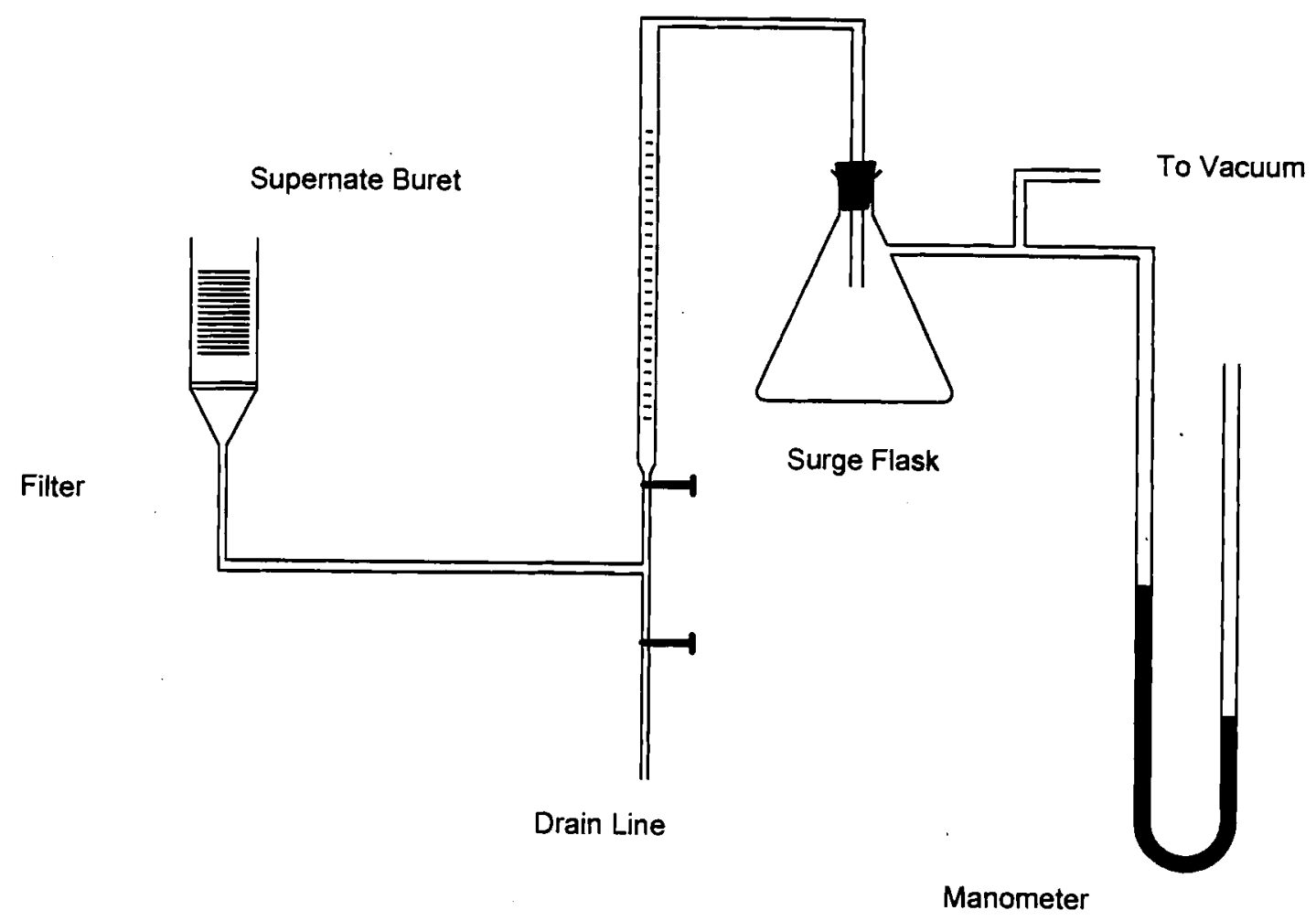

Figure 6. Diagram of Experimental Apparatus for Solvent Permeation Experiments

onto the supernate in the reservoir. The system was dewatered at the desired vacuum level (corresponding to about 1 or $1.5 \mathrm{~m}$ of supernate), using the buret to track the amount of supernate withdrawn. The buret reading and the volume of sludge in the reservoir at the point that the solvent first covered the surface of the sludge was recorded. The experiment was continued until the volume of supernate withdrawn in a 24-hour period was less than $0.1 \mathrm{~mL} /$ day, or after 300 hours.

At the completion of the experiment, the system was shut down and the solvent poured from the reservoir. The sludge was removed from the reservoir into a $50 \mathrm{~mL}$ beaker and its volume measured by filling the beaker to a known volume; the difference between the known volume and the amount of water added equalled the displaced volume. The water was drained from the sludge into a separatory funnel. A second addition of deionized water was added to the sludge to further rinse the surface and then drained into the separatory funnel. Solvent remaining on the filter membrane was rinsed off using deionized water and added to the separatory funnel. The glass frit was rinsed by applying deionized water to the top of the filter while it was under vacuum and the rinse water recovered and added to the separatory funnel. After 2 hours, the solvent was recovered from the separatory funnel. The sludge was resuspended in approximately $200 \mathrm{~mL}$ of deionized water and allowed to settle for about 2 hours in a separatory funnel to separate any free solvent from the sludge. This solvent is also recovered and measured. The quantity of solvent recovered by the different procedures were recorded individually. 
Previous tests were conducted using dodecane, $50 \mathrm{~mL}$ of a sludge simulant, and supernate used in earlier research (Gerber 1994) and at a vacuum corresponding to .75 m water showed that more than $19.1 \mathrm{~mL}$ of an initial quantity of $20 \mathrm{~mL}$ of solvent could be recovered by these procedures. These tests also showed that about $0.25 \mathrm{~mL}$ of solvent would be recovered during rinsing even though the test conditions precluded permeation of the organic. This quantity is attributed to the thin coating of solvent remaining on the sludge monolith following rinsing.

\section{Experimental Results}

Experiments were conducted with each simulant to evaluate solvent permeation under matric potentials ranging from $0.8 \mathrm{~m}$ to $1.8 \mathrm{~m}$ of supernate. These values were selected because the depth of sludge in Tank C-103 varies from 0.9 to $1.5 \mathrm{~m}$. Table 8 shows the amount of solvent recovered at the completion of each experiment, and the maximum amount of solvent that could be in the sludge based on solvent recovered from resuspended sludge and solvent not recovered. Also shown is the wt \% of water remaining in the sludge at the conclusion of each experiment, which was determined by measuring the weight of the sludge after drying it. The maximum solvent that could be in the sludge for tests $1 \mathrm{~A}, 2 \mathrm{~A}$, and $2 \mathrm{~B}$ less than $1 \mathrm{~mL}$, which is considered to be within the accuracy expected for solvent loss under conditions of no permeation.

Table 8. Experiment Results of Permeation Evaluation of Sludge Simulants

\begin{tabular}{||c|l|l|l|l|l|l||}
\hline & \multicolumn{1}{|c|}{$\begin{array}{c}\text { Simulant/matric } \\
\text { potential, } \\
\text { (m Supernate) }\end{array}$} & $\begin{array}{l}\text { Total solvent } \\
\text { recovered, } \\
\text { mL }\end{array}$ & $\begin{array}{l}\text { Solvent } \\
\text { recovered } \\
\text { from } \\
\text { sludge, } \\
\text { mL }\end{array}$ & $\begin{array}{l}\text { Final } \\
\text { weight of } \\
\text { sludge }\end{array}$ & $\begin{array}{l}\text { Maximum } \\
\text { solvent } \\
\text { in sludge }\end{array}$ & $\begin{array}{l}\text { Wt\% } \\
\text { water in } \\
\text { sludge }\end{array}$ \\
\hline \hline 1A & $\begin{array}{l}\text { Simulant 1 } \\
-0.9\end{array}$ & 19.2 & 0.06 & 34.4 & 2.0 & 73.1 \\
\hline 1B & $\begin{array}{l}\text { Simulant 1A } \\
-1.3\end{array}$ & 18.92 & 0 & 28.7 & 3.4 & 64.9 \\
\hline 2A & $\begin{array}{l}\text { Simulant 2 } \\
-0.8\end{array}$ & 19.825 & Trace & 29.3 & 0.5 & 65.2 \\
\hline 2B & $\begin{array}{l}\text { Simulant 2 } \\
-1.3\end{array}$ & 19.575 & 0.1 & 32.6 & 1.5 & 62.7 \\
\hline 2C & $\begin{array}{l}\text { Simulant 2A } \\
-1.8\end{array}$ & 18.53 & 0.0 & 51.238 & 2.6 & 60.0 \\
\hline
\end{tabular}

Experiments $1 \mathrm{~B}$ and $2 \mathrm{C}$ showed indirect evidence of significant adsorption. Total of solvent not recovered was 1.08 and $1.47 \mathrm{~mL}$, respectively, greater than that normally lost. Also, there is a trend of increasing solvent loss with increasing applied vacuum for both simulants. One difference that occurred in conducting experiments $1 \mathrm{~B}$ and $2 \mathrm{C}$ was that some solvent passed through the filter 
membrane and it is possible that at least a portion of the solvent was not recovered from the glass frit supporting the filter membrane, although about $0.2 \mathrm{~mL}$ of solvent was recovered by washing the frit with supernate with the system under vacuum.

There were two other sources of loss of solvent during recovery. The first source is a result of organic films left behind on the filter reservoir, beakers, and separatory funnels. Using the solvent recovery value for experiment $2 \mathrm{~A}$, this source would account for about $0.15 \mathrm{~mL}$ of solvent. The second source, which was not anticipated while conducting experiments $1 \mathrm{~A}, 2 \mathrm{~A}$ and $2 \mathrm{~B}$, was dissolution of the TBP present in the solvent into the water (about $200 \mathrm{~mL}$ ) used to resuspend the sludge to separate solvent. Experiments $1 \mathrm{~B}$ and $2 \mathrm{C}$ were modified to rinse the sludge and resuspend it using solvent equilibrated supernate. The fact that no solvent was recovered from the sludge in these experiments suggest that the solvent may be remaining, attached to the sludge particles even after resuspension.

One observation noted from the test results is that the finer sludge material tended to have a greater amount of solvent loss compared to the coarser sludge material at comparable levels of vacuume. At this time, there is no explanation.

\section{Conclusions and Recommendations}

Based on the experimental results, there appears to be some solvent permeation into sludge simulants under conditions representative of sludge .9 to $1.5 \mathrm{~m}$ deep. However, the amount of solvent that permeated the simulants tested was still relatively modest $(1.5 \mathrm{wt} \%$ to $3.4 \mathrm{wt} \%)$. These quantities are less than $10 \%$ of the total liquid entrained in the sludge at the conclusion of each experiment and may not cause a degradation of safety, although that remains to be determined.

There are two important points that need to be considered in evaluating these results. First, one of the samples of sludge taken from Tank C-103 in 1986 had a reported $50 \%$ volume particle diameter of $49.5 \mu \mathrm{m}$, which is 3 times greater than the $50 \%$ volume particle diameter in the coarser sludge simulant tested. Second, the interfacial tension between the solvent and aqueous phase simulants was 2 to 4 times greater than that reported for solvent and aqueous phases taken from Tank $\mathrm{C}-103$ in 1993. Both of these points suggest that solvent permeation could occur to a greater degree in the actual tank.

It is recommended that an even coarser sludge simulant be tested to better bound the coarser $50 \%$ volume particle diameter measurement for sludge samples recovered from the tank. Similarly, tests with a solvent supernate system having a lower interfacial tension needs to be tested. Further effort is also needed to determine whether the unrecovered solvent was in the sludge, and whether solvent permeating the glass frit is a significant source of solvent loss. 


\section{References}

Burger, L. L. 1984. Chapter 3, "Physical Properties" Science and Technology of Tributyl

Phosphate, Volume I, CRC Press, Cleveland, Ohio.

Carter, M. R., Ed. 1993. Soil Sampling and Methods of Analysis, Lewis Publishers, Boca Raton, Florida.

Dean, J. A. 1973. Lange's Handbook of Chemistry, 11th Ed., p. 10-279. McGraw-Hill Book Company, New York.

Freeze, R. A., and J. A. Cherry. 1979. Groundwater, Prentice-Hall, Inc., Englewood Cliffs, New Jersey.

Gerber, M. A. 1994. Waste Tank Organic Safety Project Organic Concentration Mechanisms Task FY 1994 Progress Report. PNL-10064, Pacific Northwest Laboratory, Richland, Washington.

Lenhardt, R. J. and J. C. Parker. 1988. "Experimental Validation of the Theory of Extending TwoPhase Saturation-Pressure Relations to Three-Fluid Phase Systems for Monotonic Drainage Paths,"

Water Resources Research, 24(3):373-380.

Pool, K. H. and R. M. Bean. 1994. Waste Tank Organic Safety Project Analysis of Liquid Samples from Hanford Waste Tank 241-C-103, PNL-9403, Pacific Northwest Laboratory, Richland, Washington.

Riddick, J. A. and W. B. Bunger. 1970. Techniques of Chemistry, Volume II, Organic Solvents, Wiley-Interscience, New York.

Weiss, R. L. and K. E. Schull. Data Transmittal Package for 241-C-103 Waste Tank Characterization, SD-RE-TI-203, Westinghouse Hanford Company, Richland Washington.

Wilbourn, R. G. 1977. Safety Aspects of Solvent Nitration in HTGR Fuel Reprocessing, GA-A14372, San Francisco Operations Office, U.S. Energy Research and Development Administration, San Francisco, California. 

PNL-10412

UC-601

\section{Distribution}

No. of

Copies

2 DOE Office of Scientific and Technical Information

Onsite

7 DOE Richland Operations Office

S. O. Branch S7-54

R. F. Christensen $\quad$ 57-54

M. F. Jarvis $\quad$ S7-54

G. W. Rosenwald S7-54

Public Reading Room

RL Docket File (2)

\section{FAI}

M. G. Plys

H4-62

\section{MACTEC}

M. H. Campbell

S7-73

S. T. Murff

S7-73
No. of

Copies

27 Pacific Northwest Laboratory

D. M. Camaioni K2-38

J. A. Campbell P8-08

M. A. Gerber (5) P8-38

P. G. Heasler K5-12

L. K. Holton P7-43

B. M. Johnson P1-78

S. J. Ortiz P8-38

W. D. Samuels K2-44

R. D. Scheele P7-25

G. F. Schiefelbein P8-38

C. W. Stewart K7-15

J. J. Toth K7-94

K. L. Wahl P8-08

Organic Tank Project File (4) P8-08

Publishing Coordination

Technical Report Files (5)

9 Westinghouse Hanford Company
H. Babad
S7-30
R. J. Cash
S7-15
J. M. Grigsby
S7-15
E. J. Lipke
S7-14
J. E. Meacham
S7-15
D. A. Reynolds
R2-11
D. A. Turner (3) S7-15

Distr. 1 
: 